\title{
Surveying Monitoring of the Annunciation of the Blessed Virgin Mary Church in Inowrocław, Located in a Mining Area, Applying Reflectorless Technologies and Precise Levelling***
}

\section{Introduction}

Mining activities carried out by underground mines have a considerable influence on the buildings located on the surface of the area within the range of the exploitation influence. This way it impacts in a particularly dangerous way on all the buildings and engineering constructions located directly over the old workings or within the borders of main influence. This impact means the deformation of the geometry in the solids of the building objects caused by the deflection and the strain of the surface of the terrain. The occurrence of the deformation of objects involves danger of a building disaster. To prevent from this danger from occurring geologic studies and expertise are usually made (geophysical studies, geological boring) and surveying inventories in the framework of temporary monitoring of objects located in the mining area.

In recent years the availability of modern surveying equipment made it possible to carry out reflectorless measurement of the distance directly to the examined surface and allowing obtaining precise data on the object and extent of its deformation in real time. This improved the efficiency of inventory measurements. Technologies based on measurements using modern total station instruments shortened the time and increased the accuracy of the measurements compared to older classical measurement methods. This is extremely important in the context of a great number of construction objects requiring temporary monitoring because of the threat connected with the carried out (or finished) mining exploitation. In

* AGH University of Science and Technology, Geoinformatics and Mining Surveying, Faculty of Mining Surveying and Environmental Engineering, Departament of Mining Areas Protection, Krakow, Poland

** AGH University of Science and Technology, Faculty of Mining Surveying and Environmental Engineering, Departament of Geomatics, Krakow, Poland

*** The present paper has been developed within the Statutory Research by the Department of Mining Areas Protection, Geoinformatics and Mining Surveying ref. no. 11.11.150.009 and the Statutory Research by the Department of Geomatics ref. no. 11.11.150.006 
particular it refers to the objects classed as "products of material culture", i.e. protected sacral and lay objects possessing the status of cultural monuments. Their delicate construction, large-cubature character and usual lack of security measures from the influence of mining exploitation make these buildings particularly subdued to damage or - in extreme cases - destruction. Damage that does not look very serious, such as scratches or cracks in the fragments of buildings, can be caused by negative changes in the geometry of objects, and consequently pose immense threat to buildings and their users. Neglecting the problem caused by the influence of carried out or finished mining exploitation and accompanying characteristics for salt mining suffosion and karst phenomena, can cause permanent deformation to buildings a serious threat of a construction disaster.

Access to modern laser instruments significantly simplifies and propagates the assessment methods of the technical state of the buildings of an exceptional historical, cultural and religious character. Presented in this publication are the results of measurements are based on the technology using reflectorless total station Leica TCR 303, in which an integrated laser telemeter allows for measuring a distance to any fragment without the need of signalling the target with special prisms. Apart from distance measurements, there are measurements of geometric levelling with the application of a precise code leveller Na 3003 Leica.

\section{Short Characteristics of the Salt Mine "Solno" and the Annunciation of the Blessed Virgin Mary Church}

The history of salt mining in Inowrocław goes back to the second half of the 19th century when the detected deposit was made available for exploitation on an industrial scale. Salt mining started in 1873 when many underground and borehole mines were opened at the same time [4]. Until 1873 in the area of the occurrence of the deposit, many places of salt production from natural brines were documented archeologically. Their history goes back to the beginning of the Polish state. Due to the documentation of a large salt deposit and making it available for exploitation, a rapid development of the demand for labour occurred, causing the immigration of a large number of people and the development of a little town, which soon developed into an industrial city and due to the healing properties of the brines it also became a health resort. Unfortunately:

- the specifics of the rock mass (lithology), unfavourable tectonics (the occurrence of tectonic vaults disturbing the continuity of the rock mass),

- rapidly developing chaotic mining activities, until 1924 represented by many companies (carrying out a large number of underground workings and not securing them sufficiently), 
- impact of suffusion and karst phenomena (resulting from the presence of soluble and cracked rocks in the overburden) on the rock mass,

- the lack of theory about the influence of mining exploitation on the surface and its impact on the surface, as well as the lack of the concept of the protective pillar for surface objects of particular meaning,

caused, already in the first years of the mining industry, mining damage in the form of large-surface subsidence areas of the surface, damaging or totally destroying many construction objects located on the surface [1]. One of such objects, which was seriously damaged by the subsidence in the first years of mining was the Annunciation of the Blessed Virgin Mary Church [2] (Fig. 1 - depression no. 4).

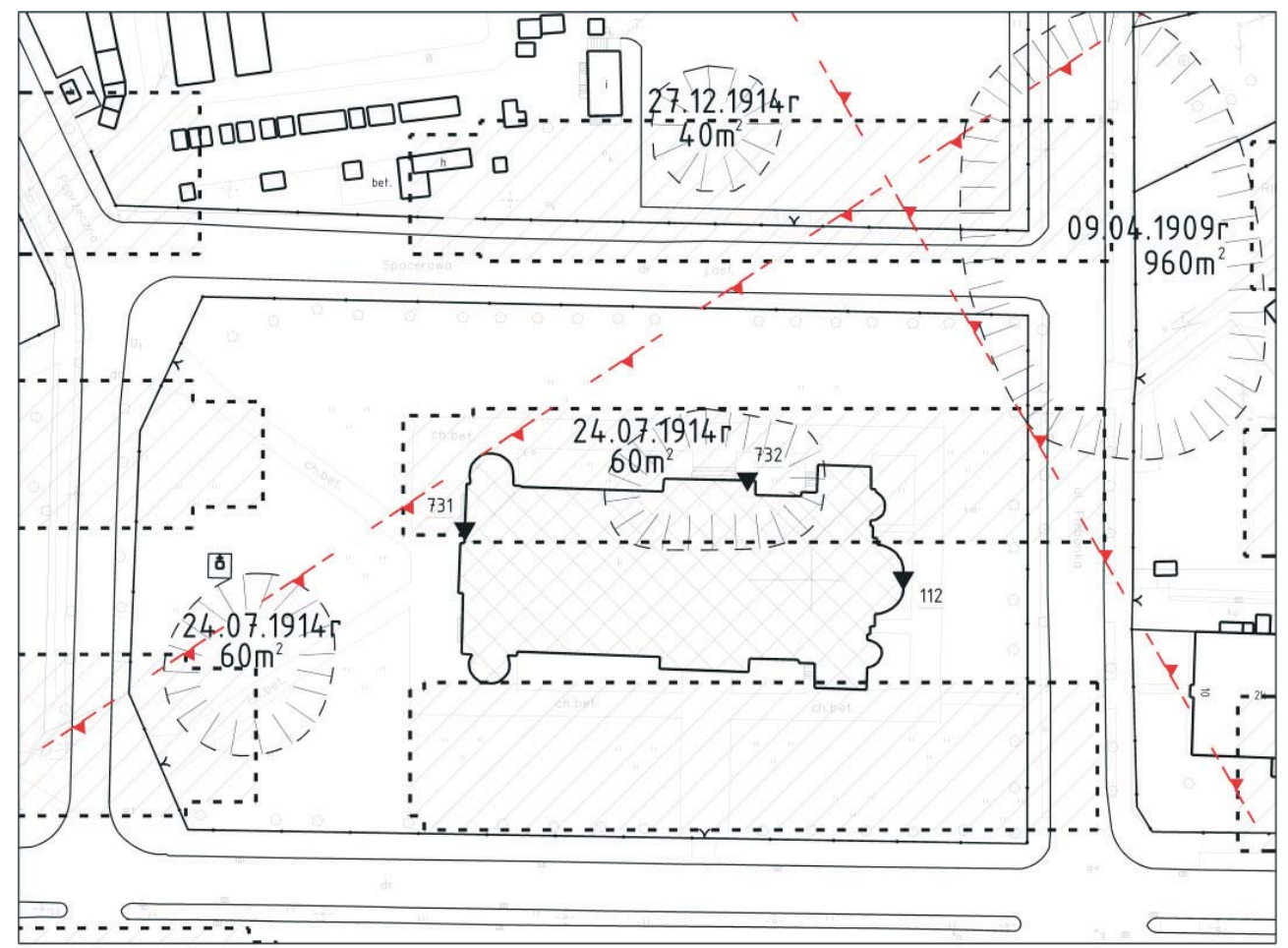

Contour line of the historical depressions

Contour line of the church

Contour line of the post-exploitation chambers in the mine

Lines of tectonic vaults

Fig. 1. Location of historical depressions in the closest vicinity of the Annunciation of the Blessed Virgin Mary Church in Inowrocław: 24.07.1914 (area $\left.60 \mathrm{~m}^{2}\right), 27.12 .1914\left(\right.$ area $\left.40 \mathrm{~m}^{2}\right)$, 24.07.1914 (area $\left.60 \mathrm{~m}^{2}\right), 09.04 .1909\left(\right.$ area $\left.960 \mathrm{~m}^{2}\right)$ 
The process of the formation of the final form of the salt mining and putting in order mining activities in Inowrocław started in 1924, when the underground salt mine "Solno" was established (only in 1932 did the first saturated brine reach consumers), consisting of 7 levels exploiting the deposit with the pillar-chamber system. The deposit was located at a depth between $470-578 \mathrm{~m}$. Access to it was through the small ( $3 \mathrm{~m}$ diameter) shaft Solno I (www.geo.uw.edu.pl/SOLNO). Only the need for the development of the mine and making available subsequent mining fields for the exploitation in 1960, made the enterprise build a new shaft Solno II, requiring tubing, because of the water hazard requiring freezing of the rock mass.

Exploitation in the mine "Solno" was carried out until 1986. During the work of the mine, i.e.: 1924-1986, over $100 \mathrm{mln} \mathrm{m}^{3}$ of industrial brine was produced, while under the city over $15 \mathrm{mln} \mathrm{m}^{3}$ of workings remained. Due to a large number of empty underground cavities and potential threat for the developing city and its infrastructure, in 1986-1991 the process of its liquidation started with filling the workings with saturated brine. The mine, despite its enormous natural values formed by unique mining workings and natural caves, was made available for tourists for the centenary of the salt industry in Inowrocław (1973). The presence and consequently threat from methane, hydrogen sulphide, carbon dioxide, and nitrogen dioxide, made this object unavailable for ordinary people, for almost the whole period of is existence.

Underground mining activities carried out directly under the building of the church built in 1898-1901 in the neo-gothic style from the initiative of Rev. Antoni Laubitz (according to the project by August Rincklake) (Fig. 2). The church was named after the Annunciation of the Blessed Virgin Mary. The exploitation brought mining damage. Due to the flooding of this part of the mine and suffosion-karst phenomena the solid of the church was affected. In consequence, in 1909 the top wall of the transept from the northern part detached and collapsed (www.regionwielkopolska.pl/katalog-obiektow/kosciol-pw-zwiastowania-nmp-w-inowroclawiu.html).

The disaster of 1909 removed the church from the function for 20 years. Only in 1929 did the church renew functioning. For more than 100 years the building has been subdued to the impact of the exploitation, although nowadays the influence comes only from the historical exploitation. This does not mean that the rock mass has stabilized. From the studies carried out since 2005 [2] it can be concluded that the area of the parish is situated on the slope of the post-exploitation trough and is constantly being uplifted (reference of height measurements to the wall height notch mark no. 126 at the Toruńska street, situated beyond the borders of the mining influence), however, the solid of the church itself behaves as if it was situated on a "cushion" due to (among others) the heterogeneity of the bed. 


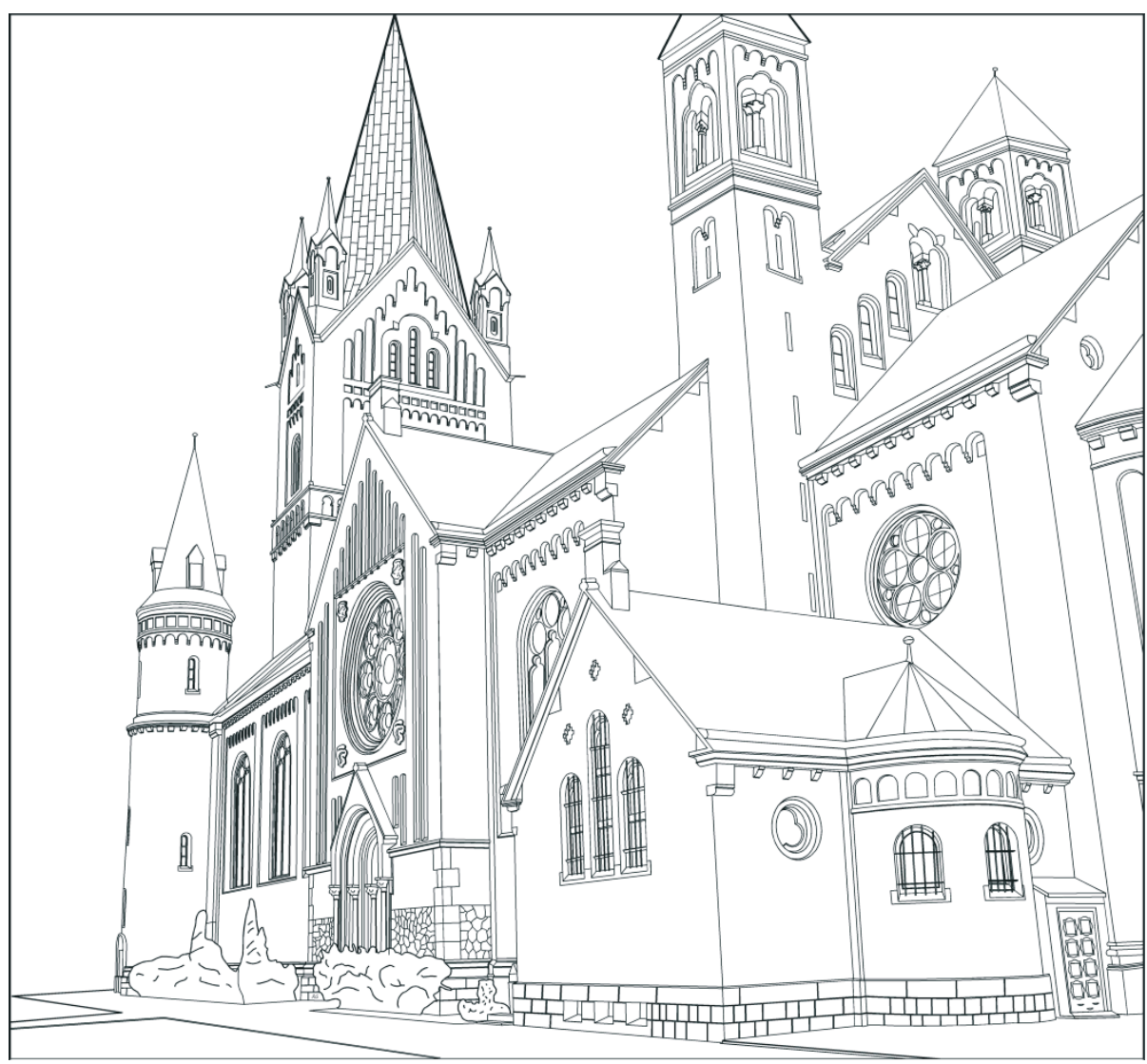

Fig. 2. The Annunciation of the Blessed Virgin Mary Church in Inowrocław - view from the south-east

Delicate construction of a monumental character is extremely sensitive to even slight movements of rock mass (bed). A characteristic element of this object, which dominates over the city, is a huge $76 \mathrm{~m}$ high spire (Fig. 2), with a very large rosette window and highly ornamented portal. Three-ale character of the church [4], of the dimensions: length $63 \mathrm{~m}$, transept width $27 \mathrm{~m}$, makes the object very sensitive to all the changes in the morphology of the bed. Apart from the uneven subsidence of the elements of the building construction (pillars, pilasters) also the floor and ceilings of the ales were deformed. A particularly dangerous effect of these deformations include scratches and cracks (often with dislocations) on the walls and ceilings being a result of the uneven strain of the bed. These phenomena became the source of the deformation of the building, and this way contributed to undertake all the activities aimed at the definition of the degree of the deformation of main elements of the object in the framework of the carried out surveying monitoring. 
At the moment one can also assume that consecutively appearing cracks and scratches can come from micro-tremors of the ground, caused by road transit taking place in the vicinity of the building (A. Laubitz street). This phenomenon is known to conservators at the the Royal Castle on the Wawel Hill. They detected the scratches and cracks of the walls in the south-east part of the complex and they associate them with the tremors originating from traffic on the Grunwald Bridge, situated a few hundred metres from the monument.

Carried out in 1873-1991 mining exploitation in the area of the city of Inowrocław, caused quite serious damage to the structure: construction walls, windows of side ales, ceilings of the main ale including the ale-transept dome (the highest part of the ale - over $17 \mathrm{~m}$ ), pillars between windows. It is also important to register the changes of the deflection of particular components of construction (pillars, pilasters, edges of walls) in the course of further preventive measures in the construction work in the future, with the task of safe preservation of the object in a usable state. The carried out by the authors analysis refers to the period 2005-2010, the time when in 2008-2009 security works were carried out. They included strengthening the main construction elements of the ale part of the building at the level of about $8 \mathrm{~m}$ over the floor. Repeating the measurements in the 5 year internal, preserving the same measurement set of the same reference points (situation-height control line) and similar atmospheric conditions make the observations equally accurate, while the results are reliable and conclusive. The obtained from autumn measurement of 2010, values of deflections or height changes in selected points, can make reference for further possible deformations arising after taking security measures.

\section{The Description of the Accepted Premises of Height Analysis and the Obtained Results}

Due to the different characteristics of the accuracy of the applied surveying monitoring technologies of the way of obtaining data in different fields:

- levelling-height measurement,

- reflectorless (total station) - situation measurement,

in the article two directions of the deformations in the main part of the building are discussed.

Based on the levelling network method, in 2005 the primary measurement of floor was made with the application of precise code leveller Na 3003 Leica. Imaging the morphology of a large surface of the floor in ales and presbytery (185 measurement points on the surface $921 \mathrm{~m}^{2}$ excluding pillars), allowed for a precise description of height differences in values, direction, and variability of 
the deformation values. This means that on the whole surface of the church the deflection in the north-west direction is observed, according to the direction maximal deflection of the slope of the subsidence trough for the examined area.

So far in the literature [2], an analysis of height changes of selected elements in the main part (ales) of the church was carries out in the system of absolute altitudes (Kronsztadt system). Transferring heights from constant points of the state control line (located beyond the limit of mining influence) on the points situation-height control line of the church, i.e.: points of the church observation network (fundaments of the building - see Fig. 3, points stabilized in the floor, points of the measurement control line), were carried out using precise levelling technology. Large distances to the reference point always causes a transfer of the levelling error on the height of points marked in a given measurement, although it does not have any major influence on the obtained internal accuracies, i.e. within the network of the observation points of the examined object. The principle of such a reference is obtaining information on the general situation referring to the state of the examined object and the adjacent area, in terms of their subsidence or uplift. For sub-millimetre values of changes, a better visualising method seems to be operating in the analyses with the changes in the height differences between the neighbouring points in time, especially while assuming the high accuracy of the measurement.

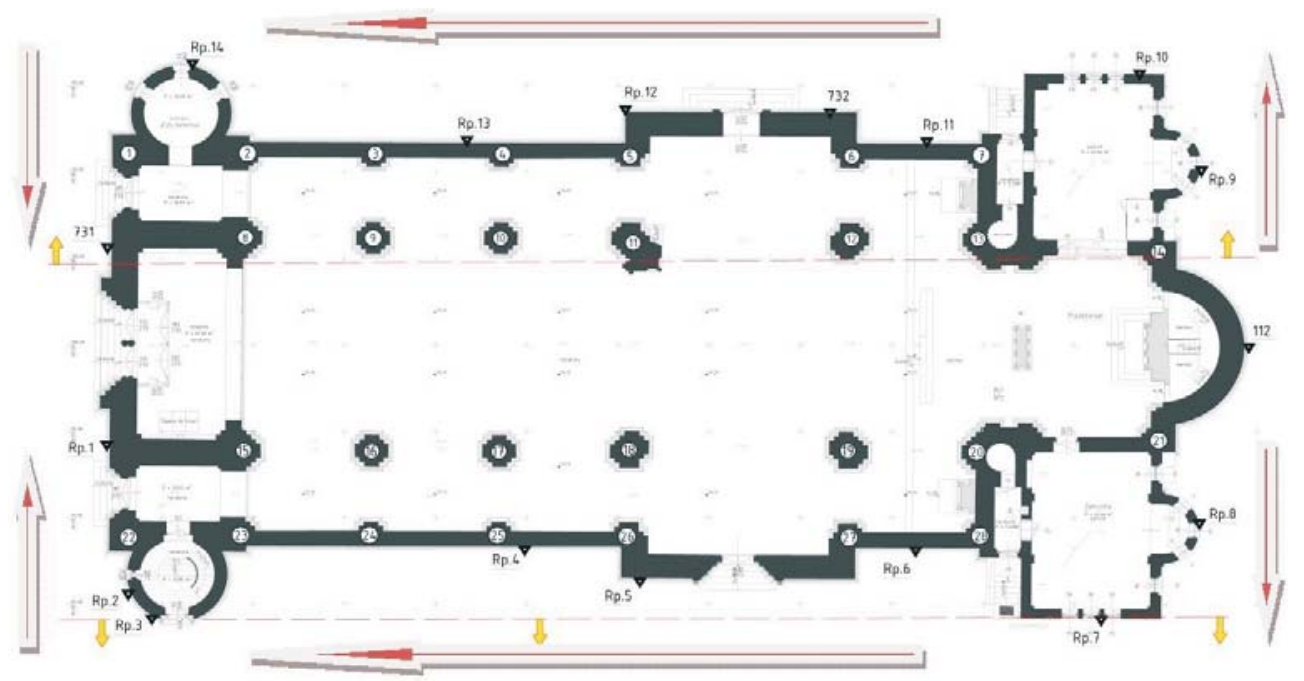

Explanations:

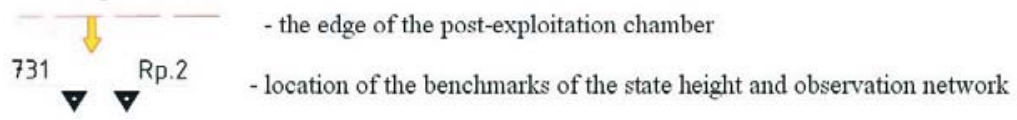

Fig. 3. Localization of the observation points of the height control line stabilized on the base 
Levelling studies included the measurements of the differences in the height between the neighbouring benchmarks in chains following the scheme presented in figure 3.

To find the accuracy of the analysis and regard the variability of not only the values of height differences $\Delta H$, but also their signs (effect similar to "floating" of subsequent parts of the fundament) directions of the analyses on individual bays were accepted following the scheme as in figure 4 .

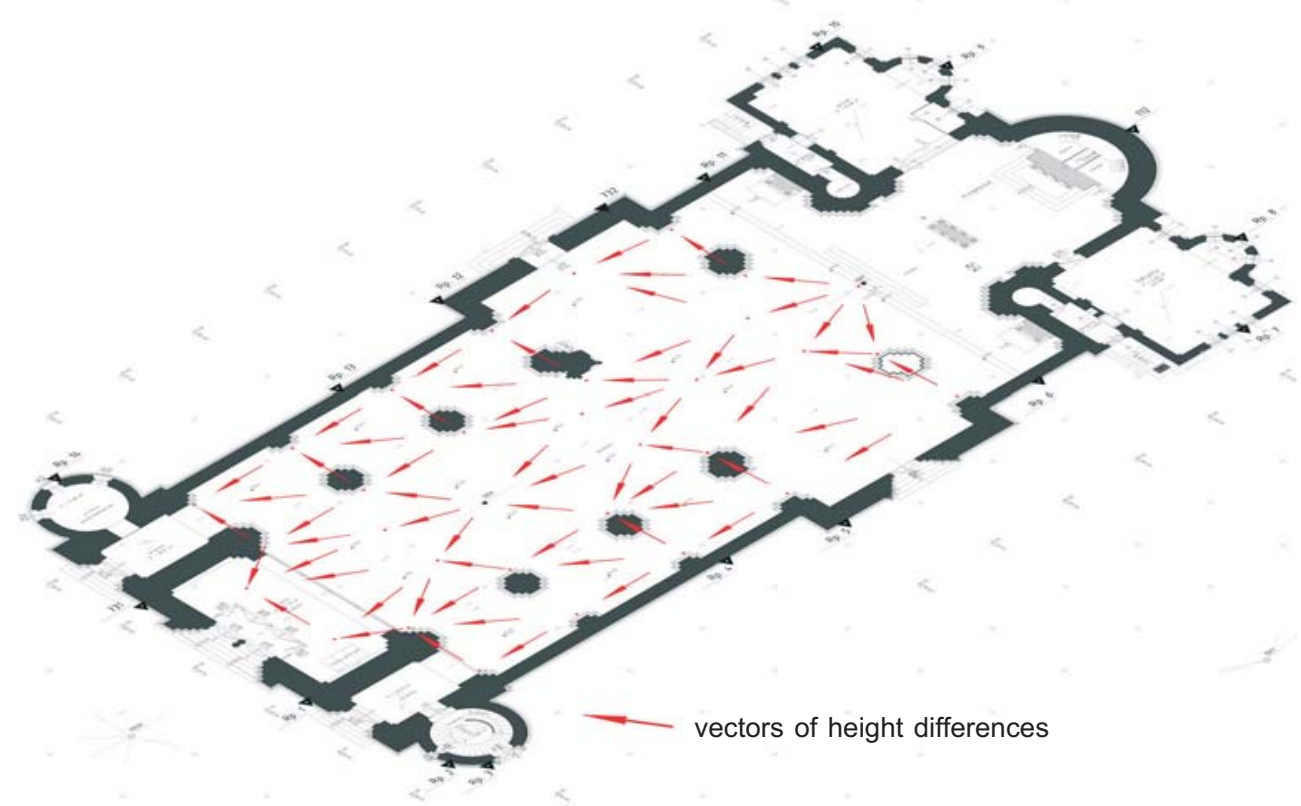

Fig. 4. The scheme of the triangulation network - vectors of the marked height increases in the primary measurement (2005)

The analysis based on the system of relative heights or their increase, provides the isolation of the data from the possible influence of errors in one-point or multi-point reference. The obtained results have only errors depending on the precision of the measurement technology itself at the stage of marking individual height differences. Thus, if the measurements were made with the application of code leveller Na 3003 Leica, where the accuracy of the measurement in a single levelling for the precise mode is $\pm 1.4 \mathrm{~mm} / \mathrm{km}$, assuming maximal bay length equalling $25 \mathrm{~m}$, one can accept accuracy of defining the height difference at the level $m_{\Delta h}= \pm 0.04 \mathrm{~mm}$. Thus, it is reasonable to accept a minimal value of the gradient in the isoline $s$ for isoline maps showing changes in the geometry of selected construction elements and other elements (e.g. floor), at least at the level of limit 
error $3 m_{\Delta h^{\prime}}$ which in this case is $3 m_{\Delta h}= \pm 0.1 \mathrm{~mm}$, thus the value is reliable and conclusive.

In the final analysis of the height changes in the points of the base, the comparison of height differences between them in different time intervals of 2005-2010. Due to the variability of the value and signs of height differences between points in the accepted analysis chains, it was necessary to establish the direction of the analysis to correctly take into account the signs of these changes. The direction of the analysis was in figure 3 marked in symbol ( the marked parameter of changes in height differences $\boldsymbol{d} \Delta \boldsymbol{H}_{i-j}$ for a given bay, was attributed to its centre. The value of the change in height difference $d D H_{i-j}$ for a given section was taken from the formula:

$$
d \Delta H_{i-j}=\Delta H_{i-j_{[2006,2007,2010]}}-\Delta H_{i-j_{2005}}
$$

From the analysis it can be concluded that the highest changes in parameter $d \Delta H_{i-j}$ occurred close to the top walls of the transept, both from the northern and southern side (especially in 2005-2006).

How dynamically the situation inside the analyzed sacral object changed can be illustrated by the images of the distribution of changes in height differences $d \Delta H_{i-j}$, between neighbouring points of the network of the height control line points stabilized in the floor. As base measurement the data obtained from levelling in 2005 (after establishing the network) were taken. Based on the triangulation network "stretched" on the stabilized in the floor height points, based on formula (1) the values of changes in height differences $d \Delta H_{i-j}$ were determined in selected measurement periods (2005-2006, 2005-2007 and 2005-2010). Signs of the determined height increase in the primary - base measurement (2005) were taken according to the scheme presented in figure 4, where the direction (azimuth) of a given section decided on the sequence order of actions, based on the formula:

$$
\Delta H_{i-j}=H_{j}-H_{i}
$$

Thus, it shaped the sign of parameter $d \Delta H_{i-j}$. This scheme was accepted for azimuths of the sides of the triangulation network from the interval $200-400^{\mathrm{g}}$, defining real direction of the deflection of the subsidence trough slope in the region of the localization of the church.

Characteristic changes of floor geometry, as well as base geometry were seen in the section Rp. 3-Rp. 4 (southern side), in 2005-2010.

To show the morphological variability of such a large surface of the church as it is the floor of the ale part of the church, to preserve legibility of the isolines of the floor deformations - the gradient was accepted as $s=0.5 \mathrm{~mm}$. 
During the first two years visible and significant changes in the morphology of the floor were recorded in the central zone of the church (crossing between the main ale and transept) in the region of pillars no. 10, 11 and 12 (numbers given in figure 3). Changes in height differences in the triangulation network do not exceed the value $\pm 1 \mathrm{~mm}$. The situation changed significantly within a longer period (5 years), when many measures were taken to secure the solid of the church at the height of about $8 \mathrm{~m}$ over the floor.

Particular changes in the values of height differences in the network were recorded in zones:

- southern (right-side ale) within benchmark Rp. 4, where near pillar no. 24 changes in height differences reached $3 \mathrm{~mm}$;

- visible changes in the vicinity of pillar no. 11 (with the pulpit), where the flattening of the floor occurred reaching about $1 \mathrm{~mm}$;

- in the north-west part, in the vicinity of pillars no. 8 and 9 - the deflection increased by more than $1.5 \mathrm{~mm}$.

\section{An Analysis of the Changes in the Deflection Vectors in the Main Part of the Church}

The technology of the measurements of the deflections of selected construction elements in the main part of the church, was based on the distance measurements carried out with the use of the refrectorless total station TCR 303 Leica. According to the data from the producer [6], this instrument provides the accuracy of distance measurement for refrectorless mode at the level of $5 \mathrm{~mm} \pm 2 \mathrm{ppm}$.

The distances measured in the framework of the observation of the object did not exceed $60 \mathrm{~m}$ (façade) and $35 \mathrm{~m}$ (inside). Thus, a constant measurement error can be accepted, equalling $\pm 5 \mathrm{~mm}$, while the studies referring to the repeatability of distance measurements for the instruments by Leica indicate actually obtained much higher accuracies (below $\pm 1 \mathrm{~mm}$ ) [5].

The observations of deflections of individual pillars were made from two points of the control line located in the main axis of the church. The localization of measurement stands provided relatively good conditions for the measurement of visible edges of the walls, pillars and pilasters, both in their lower as well as upper parts (ledges of the walls and bases of the heads of pillars and pilasters).

For the analysis, pairs of coordinates were taken, defining the inclination of the space of subsequent edges of the defined element of the building, e.g. pillar. The more edges of a given element are observed, the more probable the value is (according to the principles of the statistics). 
Thus if every verge is replaced by vector $W_{x, y}^{i}$ defined based on components $W_{x}^{i}$ and $W_{y}^{i}$ in the accepted reference system:

$$
W_{x, y}^{i}=\sqrt{\left(W_{x}^{i}\right)^{2}+\left(W_{y}^{i}\right)^{2}}
$$

then the $W_{x}$ and $W_{y}$ of the resultant vector $W^{i}$ in case of multiplying the observation, for the definite element are defined by the equation:

$$
W_{x}=\frac{\sum_{i=1}^{n} W_{x}^{i}}{n} \text { and } W_{y}=\frac{\sum_{i=1}^{n} W_{y}^{i}}{n}
$$

thus resultant vector $W i$ is given by the formula:

$$
W^{i}=\sqrt{\left(W_{x}\right)^{2}+\left(W_{y}\right)^{2}}
$$

where $n$ - the number of edges taking part in the analysis.

This way of analysis enables averaging the observations, which are loaded with a larger error due to unfavourable conditions of falling the laser spot at the observed edge. The analysis shows that increasing the value of the deflection vector was recorded for pillar no. 12 (o 53\%) and pilasters 13 (by 47\%) and 23 (by $58 \%$ ) - while a clear reversion of the destruction process was observed for the pilaster no. 4 located in the northern wall (by 36\%). As it is shown in the text, it is difficult to forecast the behaviour of individual construction elements of the church, which in fact is situated over the complex of exploitation chambers of approximate size $20 \mathrm{~m} \times 9 \mathrm{~m} \times 100 \mathrm{~m}$, located on 7 exploitation levels separated by salt shelves of a thickness of about $9 \mathrm{~m}$, with the preservation of the width of inter-chamber pillars on the level of $15 \mathrm{~m}$ [3].

Large-surface character of the object and its unfavourable localization towards the edges of post-exploitation chambers localized directly under the object, make its delicate construction be particularly sensitive to all the movements of the bed. A particularly visible influence of the instability of the ground on the particular elements of construction (pillars, walls) is seen in the central part (common part of the main ale and transept) within the dome, which due to height changes of pillars and deflections caused by the movements of the ground, in recent years serious damage has been caused (numerous cracks with height displacement of its individual fragments).

The process of the deformation of high elements in the main part of the church as registered in 2005-2010, is characterized by high variability, both in quantitative (uneven distribution), as well as qualitative (variability of the 
directions of these changes) terms. Particularly visible changes were registered in case pillar no. 12 (Fig. 3), which, in the period of the 5 recent years was subdued to significant deflection and can make a particular threat to the ceiling in this part of the church and the pilaster of the northern walls no. 4 (Fig. 3), which was subdued to the rectification process on the other hand.

\section{Final Conclusions}

Carried out since 2005 monitoring of the Annunciation of the Blessed Virgin Mary Church in Inowrocław, based on the prepared measurement base (situation-height observation line) and the use of measurement techniques (refrectorless measurements and precise levelling) outside and inside the object, allows for conclusions on the state of selected elements of the building in time. Made by the authors complex inventory measurement in the last three months of 2010 allowed to define the values of determined so far geometric parameters, i.e.: inflection of pillars and walls of the main part of the church, changes in the height of the fundamental base and floor and defining the existing changes in the assumed time interval. Due to the fact that in 2008-2009 many security measures were carried out, mainly the stiffening of main construction elements with steel elements placed over the heads of the pillars and pilasters, thus the obtained results include not only direst influence of the moving ground on the fundaments of the building, and indirectly on other observed construction-bearing elements of the building, unknown in the value influence of tremors originating from the transit traffic in the vicinity of the church on the construction, but also the influence of preventive measures carried out in 2008-2009.

The obtained results make, however, a reliable database for further monitoring of the church in the subsequent accepted time interval which will allow defining the degree of the usefulness of carried out so far security works aimed at additional stiffening the construction and halting the deformation process of the high elements of the church.

This will also enable the definition of the influence of unstable and heterogeneous ground resulting from:

- the presence of the vault line,

- the occurrence of the suffusion and karst phenomena (the occurrence of discontinuous deformations in the vicinity of the object in the form of historic depressions),

- the impact of flooded old workings localized directly under the solid of the church and its closest vicinity), 
on the preservation of documented so far geometry of the building. Making measurements based on the same measurement "pattern" (the same points of the control line, the same technology of inventory at high accuracy of the measurement sets and the same calculation algorithm), allows for obtaining a high confidence level for the results and consequently for the predicted from the dynamics of the process of the deformation of the rock mass and buildings, changes of the determined parameters.

Results of the height analyses indicate slow a deformation process both in the case of the floor, where within 5 years changes in height differences in the applied triangulation network reached the value of $3 \mathrm{~mm}$, as well as in the fundamental girdle, where the highest changes were registered in the southern part. These changes have, however, an irregular and unpredictable character. The observations of high construction elements of the main part of the building showed also small changes in the value of deflections of irregular character. The greatest changes were registered in the south-west part of the side ale, where there was a change in the value of the deflection vector even by $2 \%$ and in pillar no. 12 , where this growth reached the value of $1.5 \%$. Also, the situation of pillar no. 4 in the vicinity of benchmark Rp. 13 should be mentioned where there was the rectification of the pillar by the value of $2.2 \%$.

Due to destructive character of visible changes in the geometry of the building (scratches and cracks), observed from the time of mine liquidation and the speed of these changes, it will be necessary to continue the monitoring in 2-year or 5 -year intervals. The directions of vector deflections of individual construction elements are strictly bound with the geometry of the subsidence trough the surface of the ground, but first of all the situation of post-exploitation, which "split" the solid alongside the main axis of the church.

The differentiation of the image of the changes in various parts of the building of values of deflection vectors and the height of the fundamental basis and floor, can result from the fact that the variability of the properties of the ground (rock mass). The variability in geomechanic properties of the rock mass combined with the impact of underground exploitation (the impact of voids), this decides about the value and character of the changes in the process of the subsidence of the surface of the area.

The rapid change of the direction of the vertical dislocation of small fragments of the ground, assuming the variability in physico-mechanical properties of the rock mass can start the process of arising unfavourable stresses in the structure of the building. This consequently makes the main cause of still arising scratches and cracks of walls, and ceilings. This if we assume that the natural movement of the salt deposit has a long-term character, we can assume that the building would be subdued to further deformations, requiring surveying monitoring. 


\section{References}

[1] Gawałkiewicz R, Jóźwik M., Szczerbowski Z.: Ocena stanu podłoża budynku kościoła pw. Zwiastowania NMP w Inowrocławiu. AGH, Kraków 2004 (unpublished).

[2] Gawałkiewicz R., Szczerbowski Z.: Użyteczność geodezyjnych pomiarów $w$ diagnostyce zabytkowych obiektów na przykładzie kościoła w Inowrocławiu. Przegląd Budowlany - Miesięcznik Polskiego Związku Inżynierów i Techników Budownictwa, no. 2, 2005, pp. 22-28.

[3] Pielok J.: Ułożenie programu badań dla opisu wpływu eksploatacji wysadu solnego w Inowrocławiu na powierzchnię i górotwór. Instytut Geodezji Górniczej i Przemysłowej AGH, Kraków 1975 (unpublished).

[4] Sikorski Cz.: Architektura kościoła p.w. Zwiastowania NMP w Inowrocławiu. Inowrocław 1998 (unpublished).

[5] Skulich M.: Ocena wptywu uwarunkowań technologicznych na wyniki określenia pozycji TCA 2003. AGH, Kraków 2002 (M. Sc. thesis).

[6] TPS300 Basic Series - TCR 303 Instrument Specifications. Leica Geosystems AG, Heerbrugg (Switzerland) 2000. 